\title{
LOS SITIOS REALES EN TIEMPOS DE CARLOS III
}

\author{
M. Victoria López-Cordón Cortezo \\ (Universidad Complutense de Madrid)
}

\section{RESUMEN}

Carlos III continuó practicando la costumbre de los desplazamientos a los reales sitios, que sus padres tomaron de los Austrias, pero introdujo cambios, tanto en la regularidad y duración de las estancias, como en quienes le acompañaban, ya que se desplazó siempre con el conjunto de su familia. Ni nacimientos, ni defunciones variaron su ritmo, pero si lo hizo un acontecimiento político: los motines contra Esquilache de 1766.

Aunque los Reglamentos de 1749 y de 1761 contemplaban las Jornadas, la parte proporcional de las Reales Casas que debía trasladarse quedó a la discrecionalidad de las jefaturas y de las necesidades del monarca y su familia. También se trasladó el gobierno, los secretarios del despacho, y una parte del personal de sus oficinas, así como los representantes diplomáticos, ya que celebraban actos protocolarios, como la presentación de credenciales y se firmaban tratados. Todo lo cual aumentó el coste de las jornadas y obligó a abordar el problema de la escasez de alojamientos, lo que generó un negocio de alquileres. En definitiva, el aumento del gasto y la misma disfuncionalidad de las cortes estacionales suscitó voces críticas, ante la falta de medidas correctoras.

PLABARAS CLAVE: Carlos III, Jornadas, Reales Sitios, Reales Casas, Familia Real, Desplazamientos, Secretarias del Despacho, Alojamientos, Críticas.

\section{THE ROYAL SITES IN TIMES OF CHARLES III}

\begin{abstract}
Charles III continued practicing the habit of traveling to the royal sites, which his parents took from the Austrias, but introduced changes, both in the regularity and duration of the stays, and in those who accompanied him, since he always moved with the group of his family. Neither births nor deaths varied its pace, but a political event did: the riots against Esquilache in 1766.
\end{abstract}

Although the Regulations of 1749 and 1761 contemplated the royal journeys, the proportional part of the Royal Houses that had to be moved was left to the 
discretion of the chiefs and the needs of the monarch and his family. Also the government, the secretaries of the Office, and a part of the personnel of their offices, as well as the diplomatic representatives moved, since they celebrated ceremonial acts, like the presentation of credentials and treaties were signed. All of which increased the cost of the journeys and forced to address the problem of housing shortages, which generated a rental business. In short, the increase in spending and the same dysfunctionality of the seasonal courts raised critical voices in the absence of corrective measures.

KEY WORDS: Charles III, Journeys, Royal Sites, Royal Houses, Royal Family, Moving, Secretariat of the Office, Housing, Criticisms.

\section{UNA CORTE EN MOVIMIENTO*}

En la vida cortesana, como en tantas otras cosas, Carlos III fue un heredero que siguió el modelo de sus padres, Felipe V e Isabel Farnesio. Quizás fuera consecuencia de su decidido apoyo a la hora de establecerse, primero en Parma y luego, en Nápoles; al recuerdo de una niñez y adolescencia bruscamente interrumpida cuando salió de Sevilla rumbo a Italia; de su carácter, metódico y poco dado a introducir novedades en su vida o en el gobierno; a su pasión por la caza o a la necesidad de espacios abiertos... en cualquier caso, nada más volver a Madrid como rey hizo efectiva su voluntad de proseguir con las jornadas reales lo antes posible. Algo tuvo que ver en ello su decepción por la capital, donde las obras del Palacio Nuevo estaban ya en su fase final. Hubo de alojarse, como había hecho su padre y su hermano, en el Buen Retiro, que no le resultó cómodo. En cambio, desde el primer momento, en el Pardo o Aranjuez, como en el Escorial y La Granja, que no conocía, se sintió mucho más a gusto, por lo que no solo prosiguió con el esquema establecido por Felipe V de tres estancias en Madrid, de unos tres meses, y el resto en los Reales Sitios, sino que alargó las estancias en estos últimos. Allí practicó sus aficiones cinegéticas, hizo corte y gobernó su extensa monarquía, aumentando el aparato administrativo que le acompañaba, despachando con los ministros y recibiendo a los nuevos embajadores. En realidad, siendo todo esto conocido, apenas se han sacado consecuencias ni del significado último de ese deseo de libertad que le permitía salir de mañana con poco séquito a cazar, con casaca de año marrón y chupa de ante; ni de la paradoja de rectificar y terminar el palacio madrileño para habitarlo tan poco.

\footnotetext{
* Un avance de este trabajo fue públicado por la autora bajo el título de "Servir y seguir al rey. Séquitos, desplazamientos y alojamientos en las "jornadas" , en el Catalogo de de la Exposición Una corte para el rey. Carlos III y los sitios reales, Madrid, Comunidad de Madrid, Patrimonio Nacional, 2016, pp.64-81.
} 
Ya fuera por su emplazamiento o por el abandono del proyecto inicial de Juvara, nada más ver las obras del nuevo palacio, lo juzgó equivocado, hasta el punto de pensar que era mejor dedicarlo a funciones administrativas y construirse otro más adecuado como residencia ${ }^{1}$. La llegada e intervención de Sabatini lo acercó más a su gusto y, finalmente, pudo habitarlo en 1764. Hasta entonces El Buen Retiro fue una morada provisional, en la que las pocas reformas realizadas se centraron en la construcción de las nuevas caballerizas. Tampoco, el llamado «mejor alcalde de Madrid», fue optimista sobre la posibilidad de convertir Madrid en una ciudad digna de ese nombre. Lo cual no impidió que mejorara sensiblemente bajo su reinado, ni resta importancia a las infraestructuras que se realizaron, ni a las rondas y paseos que se fueron abriendo, en una política no exenta de propaganda, que Esquilache y Aranda, auspiciaron. Los mejores edificios se situaron en puntos clave, lo mismo que se dignificó sus accesos con hermosas puertas como la de Alcalá, pero también la de Toledo y la desaparecida de San Vicente. Igualmente, el clasicismo se adueñó de las fuentes y el Prado de Recoletos mereció el título de salón. Hubo también una gran concordancia entre la política reformista y proyectos como la Real Casa de Correos, confiada en 1760 a Marquet, la Real Casa de la Aduana, el Hospital de San Carlos o el destinado a acoger el Real Gabinete de historia Natural, de los cuales solo los dos primeros quedaron concluidos.

Pero, ni el monarca, ni sus ministros, se aventuraron en operación urbanística de envergadura en el entramado urbano, ni siquiera en el entorno del nuevo palacio, prefiriendo limitarse a intervenciones más prácticas, desagües, limpieza y enlosado, que intentar modificar la estructura de una ciudad que, como decía Ponz, había nacido sin plano ${ }^{2}$. Sin embargo, no pasó lo mismo en los reales sitios, donde se compró, proyectó y construyó con objeto de acoplarlos a las nuevas necesidades, procurando siempre que no perdieran el carácter natural de sus emplazamientos y siguieran los criterios del urbanismo ilustrado ${ }^{3}$.

$\mathrm{Ni}$ antes ni después de la llegada de los Borbones, la itinerancia estacional fue un hábito exclusivo de los monarcas españoles ${ }^{4}$. Las estancias reales en distintas residencias fueron habituales en otras que, también, por similares razones administrativas, fijaron su capital. Cuando los Borbones franceses o, mejor dicho, Luis XIV, eligió Versalles como residencia permanente, con el consiguiente

${ }^{1}$ Carlos III: cartas a Tanuci (1759-1763). Prólogo de Gonzalo Anes. Introducción, transcripción y notas de Maximiliano Barrio (Madrid: Banco Bilbao Vizcaya, 1988), 24.

${ }^{2}$ Francisco Javier Plaza Santiago, Investigaciones sobre el Palacio Real Nuevo de Madrid (Valladolid: UVA, 1975); Delfín Rodríguez Ruíz, coord., Francisco Sabatini. La arquitectura como metáfora de poder (Madrid: Electo, 1993); José Luis Sancho, "Madrid y los sitios reales" en Una corte para el rey. Carlos III y los Sitios Reales, Madrid, (Madrid: Comunidad de Madrid/Patrimonio Nacional, 2016), 95-114.

${ }^{3}$ Sobre las reformas en los sitios, José Luis Sancho "Carlos III, de monte en monte. Cinco poblaciones para una corte”, en Una corte para el rey, 115-175.

${ }^{4}$ José Luis Sancho y Gloria Martínez, “¿Dónde está el rey? El ritmo estacional de la corte española y la decoración de los reales sitios (1650-1700)", Cortes del Barroco. De Bernini y Velazquez. a Giordano, eds. Fernando Checa, (Madrid: Acción Cultural Española/Patrimonio Nacional, 2003), 8597. 
abandono del palacio del Louvre, no renunció a seguir viajando regularmente a distintas residencias en la región parisina, Fontainebleau, en invierno, Marly en primavera, Cambiègne y Choisy en verano y ese modelo, vivido por Felipe V, se sumó a la práctica española que igualmente asumió. Se suspendió durante el traslado de la corte a Sevilla, donde se trasladó el gobierno y ciertas ceremonias, como la recepción de embajadores. Desde allí los monarcas viajaron y residieron en otros lugares de Andalucía, en un circuito específico. De nuevo la corte en Madrid, la quema del Alcázar en 1734, al poco de volver a instalarse en la capital, obligaron a fijar la residencia real en el Buen Retiro, pero no cambió las salidas a los Sitios, ni el pasar las grandes fiestas religiosas de Navidad y Semana Santa en la capital.

Según el testimonio de Christoph Plüer, predicador de la embajada danesa en Madrid entre 1759 y 1765, fue con motivo de la construcción del Palacio de la Granja, en 1721, cuando se inició la costumbre de que los ministros extranjeros se desplazaran con él, lo cual fue habitual en los reinados posteriores ${ }^{5}$.

De Sevilla y no de Madrid salió en 1731 el infante D. Carlos a tomar posesión del ducado de Parma. Cuando volvió, 28 años más tarde, tras desembarcar en Barcelona, el 17 de octubre de 1759, tardó casi tres meses en llegar a la Corte. Primero fueron los festejos que prolongaron su estancia en la capital catalana; después, ya en Zaragoza, el sarampión que afectó a toda la familia real y la consiguiente cuarentena que prolongó la estancia, de manera que no llegaron al Buen Retiro hasta el 11de diciembre. Allí permaneció cuatro meses, ya que los actos públicos del recibimiento, los besamanos y la organización de la Real Casa acapararon todo su tiempo. Solo el día 15 de abril pudo marcharse a Aranjuez, acompañado por la reina, los infantes, la reina madre y el infante D. Luis, inaugurando el ciclo de los sitios. A primeros de septiembre de 1760, la familia real, tuvo que abandonar San Ildefonso y, tras pasar, solo una noche en El Escorial, salir precipitadamente el día 11 hacia el Buen Retiro, donde la reina murió el 27 de septiembre. Ya viudo, el 7 de enero de 1761 Carlos III inició sus estancias en el Pardo que apenas se había utilizado desde 1746, por lo que hubo que a acondicionarlo antes ${ }^{6}$. La fecha convenida era al día siguiente de Reyes, después de asistir a la Misa mayor que oficiaba en el Real Monasterio de San Jerónimo el Arzobispo de Farsalia e Inquisidor General, Manuel Quintano Bonifaz. Con la excepción del año siguiente de 1762 en que la erisipela del infante D. Luis, obligó a posponer la marcha, su propósito se cumplió hasta su muerte. Allí permanecía hasta el final de la cuaresma en que volvía a Madrid y, también, solo en una ocasión, en 1764, interrumpió la estancia, con motivo de los desposorios de su hija María Luisa con el archiduque Leopoldo de Austria, ya que volvió a Madrid el 10 de febrero para asistir a los festejos preparados por el embajador austriaco, conde de Rosemberg y

\footnotetext{
${ }^{5}$ Hiltrud Friederich-Stegmann, La imagen de España en los viajeros alemanes del siglo XVIII (Alicante: Universidad, 2014), 100-102.

${ }^{6}$ AGP. Administrativa. Casa, Leg. 785.
} 
los representantes de las monarquías de familia, Francia y Nápoles. Nada más acabarse, volvió al Pardo el 25, donde prosiguió su estancia hasta el 7 de abril ${ }^{7}$.

El inicio de la estancia en Aranjuez era variable, pues dependía de la celebración de la Pascua y esta de la cuaresma. Solía permanecer hasta mediados de junio y, ya a partir de 1767, hasta finales de ese mes, en que volvía a Madrid, por dos o tres semanas, antes de trasladarse a La Granja. Solo en 1766 la corte no pasó por Madrid, sino que se marchó directamente, en una de las estancias más largas en ese palacio, 125 días, entre el 25 de marzo y el 21 de julio. Por el contrario, en 1782 la estancia fue breve, 67 días, ya que el 8 de junio se trasladaron a Madrid, para marcharse de nuevo el día 14, con destino a San Lorenzo, y al día siguiente a Ildefonso, para que allí tuviera lugar el inminente parto de la princesa de Asturias. También fue prolongada la estancia en el año 1788, el último de vida del rey, 115 días, entre el 8 de marzo y el 30 de junio. La celebración del Corpus y la procesión correspondiente era un acontecimiento importante, una fiesta recuperada por Fernando VI, en 1747, tras estar veinte años suspendida, y mantenía todavía la carga festiva y pagana que le había caracterizado. A ella acudían para formar parte del cortejo capellanes y músicos desde Madrid y, también, público diverso, incluido personal de la administración, de las embajadas o viajeros ${ }^{8}$. Sus gastos, que oscilaron entre los 9.000 y 14.000 a lo largo de todo el reinado, corrían a cuenta de la Real Casa y correspondían en su mayoría a las mesillas de cantores y clérigos?

Las estancias en El Escorial y La Granja de San Ildefonso estaban relacionadas. En el viaje de ida, con el calor del verano, El Escorial era una escala, hacia el palacio de verano. En el retorno hacia Madrid, sin embargo, allí se detenían desde finales de septiembre hasta diciembre. En San Ildefonso pasaban unos dos meses y medio. Allí se celebraron los desposorios del príncipe de Asturias y María Luisa de Parma, el 3 de septiembre de 1765. Entre ambos sitios pasaban unos 130 días, excepto en 1782, en que estuvieron 174, por nacimiento de la infanta María Luisa, el 6 de julio.

En el mejor de los casos, el rey estaba en Madrid en torno a un mes entre diciembre y el siete de enero, unos 15 días entre marzo y abril, y entre 20 o 25, de finales de junio y mitad de julio. Menos de dos meses y medio al año, si tenemos en cuenta que, entre unas y otras jornadas, hubo muchas estancias breves, en los propios Reales Sitios, como la de Aranjuez sobre el 10 de diciembre, las de Riofrío o para las batidas, como las de Cuerva.

\footnotetext{
${ }^{7}$ AGP. Carlos III, Leg. 210/2. Fiestas por la boda de la Sra. Infanta María Luisa.

8 Selina Blasco, "Viajeros por Aranjuez en el siglo XVIII. Antología de descripciones" en El Real Sitio de Aranjuezy el arte cortesano del siglo XVIII (Madrid: Patrimonio Nacional, 1787), 41-136.

${ }^{9}$ AGP. CIII, Leg. 102/1. En junio de 1767 los gastos para la procesión, incluidos 30 cantantes de misa y coro, sumaron $10.604,26$ rs.
} 
La regularidad a veces también se alteró por motivos familiares como la enfermedad de D. Luis o el agravamiento del estado de salud de María Amalia de Sajonia. La incidencia de los partos de la princesa de Asturias, se limitó al año 1782, ya que se adecuaron al ritmo de las jornadas, dado que de sus 14 hijos nacidos vivos solo el infante Carlos María Isidro y la Infanta María Isabel lo hicieron en Madrid. En algún caso, como el de la infanta María Amalia, tuvo lugar a los dos días de haber llegado al Pardo. La reina madre Isabel Farnesio, murió en Aranjuez el 10 de julio, desde donde la familia real se marchó a San Ildefonso, quedando al cuidado del marqués de Montealegre, el mayordomo mayor, el traslado del cadáver para ser enterrada en la colegiata, junto a Felipe V. Dos hijos y cinco nietos del monarca fallecieron en los sitios: D. Francisco Javier, en Aranjuez, a causa de las viruelas, el 10 de abril de 1771; D. Gabriel, el favorito del rey, murió el 23 de noviembre de 1788 en El Escorial, también de viruelas. Le había precedido, su esposa, la infanta Mariana Victoria de Portugal, el 2 de noviembre, que acaba de parir y la criatura, el infante D. Carlos José, el día 9, de la misma infección. Dadas las circunstancias, el 14 de ese mes se trasladaron al Palacio madrileño los infantes nietos, por precaución, quedándose el rey con los príncipes y los infantes Don Antonio y Doña María Josefa.

Solo hubo un acontecimiento político que turbó el ritmo de los traslados, el motín contra el Esquilache, en marzo de 1766. Iniciados en Madrid el 23 de marzo, domingo de Ramos, el rey pudo contemplar los revoltosos desde Palacio, donde recibió al fraile franciscano que actuaba como portavoz e, incluso, salió al balcón de Palacio para tranquilizarlos. Pero el martes 25 se marchó a Aranjuez y no volvió hasta el 1 de diciembre. Que esos sucesos le conmovieron profundamente está fuera de duda. Y también aumentaron sus recelos respecto a la capital. El carácter anecdótico con que se reviste su transcurrir madrileño difumina el impacto de unas imágenes que sirvieron en 1787-1789 como referencia para entender lo que estaba ocurriendo en Francia. Su consecuencia fue un mayor control policial de la corte y una vigilancia extrema sobre cualquier atisbo de desorden. En 1783, por ejemplo, el marqués de Villena, caballerizo mayor del rey, trasmitió al marqués de Valdecarzana, sumiller de corps, para que este, a través de Floridablanca, previniera a la sala de Alcaldes de Casa y Corte, sobre la presencia en Madrid de personas disfrazadas, con «capotones pardos, burdos o de otros colores, sobrepuestos de labores ridículas de diferentes colares chocantes y que este traje solo lo han visto en Castilla hasta ahora los llamados gitanos, contrabandistas toreros y carniceros con quienes se equivocan a cada paso dichas personas». Una muestra de lo presente que seguían aquellos sucesos y del convencimiento de que no habían sido estrictamente populares ${ }^{10}$.

Más allá del carácter anecdótico que pueda tener la rutina de los viajes reales a los Reales Sitios y las incidencias que los alteraron, otra realidad se hace evidente: la importancia de la regia familia en la vida de la corte y en los distintos lugares de residencia, así como la voluntad del rey de una vida y de una representación conjunta.

10 Aranjuez, 5 mayo1784. AGP. Reinados Carlos III. Leg. 210/1. 
Un acompañamiento que generaba la necesidad de más personal de servicio y de nuevos alojamientos y que multiplicaban los convoyes que salían y entraban de Madrid.

\section{SERVIR AL REY EN LOS REALES SITIOS}

Ni la Casa del Rey, ni el monarca cambiaban su rutina por el hecho de no residir en el palacio madrileño, aunque sí variaba el número de los servidores que la atendían. En la composición del séquito que debía acompañarle, los cargos más inmediatos eran a propuesta del rey, pero las jefaturas de los oficios dependían del mayordomo mayor y eran los elegidos quienes a su vez proponían a aquellos de sus subordinados que debían desplazarse. En todos los casos la elaboración de las listas para los desplazamientos se hacía con bastante antelación, aunque se seguían ajustando casi hasta las vísperas del viaje.

Cuando llegó Carlos III y hasta 1761, el vasto conjunto de la Casa Real, se organizaba de acuerdo con el Reglamento de 1749, elaborado por el marqués de la Ensenada. En él se mantenían nueve dependencias, Casa del rey, Real Cámara, la Casa de la reina, Caballeriza del Rey, Caballeriza de la Reina, Casa de los caballeros pajes, Real ballestería, la Real Capilla y Casa de la reina Madre ${ }^{11}$. La primera autoridad era el mayordomo mayor y todas tenían un número fijo de personas con sueldos proporcionados a su categoría y el grado. El Reglamento contemplaba también las salidas a los Sitios Reales y la servidumbre que iba a las Jornadas, fijando las mesillas por día de desplazamiento en un máximo de 5 rs. diarios ${ }^{12}$. También se regulaba los animales y carruajes que correspondían al personal para el traslado, según los mismos criterios.

La normativa nunca se cumplió del todo. Sin embargo, fue la referencia que se tomó cuando el infante D. Carlos, ya rey de Nápoles, quiso poner en marcha su casa $^{13}$. No se copió, sino que se acopló a las circunstancias específicas de aquella corte formada por españoles e italianos. Se introdujeron cambios, el más importante, la unión de las dos casas principales, que pesaron decisivamente en las medidas que se tomaron en España después de la muerte de la reina María Amalia. Hasta entonces esa unión, por razones económicas, era un objetivo siempre presente pero fallido, por la oposición de las regias consortes. Pero, a partir de los Reglamentos de 1761, hubo en España solo una Casa, una Caballeriza y una Capilla ${ }^{14}$. La única modificación introducida fue el desdoblamiento de la figura del contralor grefier en

11 Carlos Gómez-Centurión, "La Reforma de las casas reales del Marques de la Ensenada" en Cuadernos de historia Moderna, 20 (1998), 59-83. 13.

12 Reglamento de 18 de marzo de 1749 en AGP, Administrativa, leg. 468 y 939; BNE, mss. 4313, art.

13 AGP. Carlos III, leg.138. R. D. pidiendo informes a los jefes de la Casa del Rey y de la Reina Madre sobre el número de empleados de sus respectivos departamentos.

${ }^{14}$ Reglamento General de la Real Casa de 1761 (AGP. Administrativa, leg. 939). 
dos cargos, y la separación en la Real Caballeriza de los de veedor general y contador $^{15}$. Las cámaras reales se mantuvieron separadas, aunque al no haber reina efectiva, sus servidoras y la familia de mujeres que atendía a los infantes niños e infantas, quedaron integradas en la del rey. Se mantuvo la casa de la reina madre Isabel Farnesio hasta su muerte, a la cual perteneció hasta entonces, el infante D. Luís $^{16}$. El nuevo reglamento reforzó la autoridad del secretario de Hacienda sobre los órganos de gestión y la supervisión de las consignaciones y gastos otorgándole la competencia de nombrar al contralor y el grefier, mientras que cualquier alteración en la plantilla quedaba sujeta a la del titular de Gracia y Justicia. La Real Junta de Obras y Bosques, reducida a funciones de justicia en 1754 desde la llegada de Wall a la secretaría de Estado, incorporó a su departamento los negocios que administraba. Respecto a los Reales Sitios, una Real Cedula de 24 noviembre de 1768 transfería la competencia sobre los mismos al primer secretario de Estado, entonces Grimaldi ${ }^{17}$.

El Reglamento de 1761 no hablaba sobre la organización de la Casa en los sitios reales. Se limitaba establecer que competía al mayordomo mayor nombrar a los directores de carruajes, encargados de vigilar «que no se abuse al tiempo del reparto de las jornadas» (Art.28). Como había habido muchos abusos, se les encomendaba no dar transporte más que a los nombrados, que debían presentar un boleto del contralor general que lo ratificara (art.29). También se tenían en cuenta las mesillas, pero no sin fijar su cuantía, limitándose a insistir en que se pagaran por los días efectivos de ausencia de Madrid, más los correspondientes a la ida y la vuelta (30). Nada se decía sobre la parte proporcional de la planta que debía trasladarse a los sitios, que quedaba a la discrecionalidad de las jefaturas y de las necesidades del monarca y su familia. No a todos los lugares se desplazaba el mismo número de personas, pero los jefes de la Casa acompañaban siempre al rey, mientras que, quienes dependían de ellos, lo hacían de manera rotatoria.

El mayordomo mayor, a quién correspondía «el ejercicio y la servidumbre» cerca del rey y la organización general de Palacio, era figura imprescindible en cualquiera de las residencias y en la preparación de los traslados ${ }^{18}$. Lo fueron con Carlos III, el duque de Alba, a 1760, el marqués de Montealegre, entre esta fecha y 1781, el duque de Medinaceli, hasta 1787 y desde entonces a 1802, el marqués de Santa Cruz. Bajo su autoridad, según la nueva planta, había 8 mayordomos de semana, dos más que en la de 1749, 12 gentileshombres de boca y 10 de casa y la secretaría correspondiente a su cargo ${ }^{19}$. En las jornadas, tanto los mayordomos de semana, como la secretaría, eran imprescindibles, trasladándose de los primeros cuatro que rotaban trimestralmente. Al final del reinado, en que aumentó su número

${ }^{15}$ José Jurado Sánchez, El gasto de la Casa Real. Su financiación y sus repercusiones hacendísticas y económicas, (Madrid: I. E. Fiscales, 2000), 45-48.

16 AGP Carlos III, leg. 275. Reglamentos de la Casay de la caballeriza de la casa de la Reina madre de 25 de febrero de 1761.

17 Real Cédula de 24 de noviembre de 1768, (Madrid: Oficina de Atanasio Sanz, 1768).

18 Ordenanza y reglamento que mandó hacer el rey en 1761. AGP Administrativa, leg. 941/1.

${ }^{19}$ AGP Administrativa. Leg. 924 Plantas. Nov. Rec. Libro II, tit. XII, ley II. 
a seis, la rotación, en general, respetaba los turnos ${ }^{20}$.

En la Cámara, el sumiller de corps mantenía en planta los 6 gentilhombres de Cámara y 18 ayudas de cámara en las tres clases en 1749. Entre ellos quedaron incluidos los que procedían de Nápoles, con lo que la plantilla se desajustó. De ahí provenía quien fue sumiller de corps de Carlos III entre 1759 y 1783, José Fernández Miranda Ponce de León, duque de Losada, su hombre de confianza ${ }^{21}$. Había tres categorías de gentileshombres: los que lo eran con ejercicio, que acompañaban al rey en todo momento; los de entrada, llamados así por tenerla en la sala de Grandes y los honorarios, que no estaban en planta y solo gozaban de la insignia de la llave. No había un número fijo, sino que el rey concedía los nombramientos según «su voluntad, sin propuesta de nadie», pero solo los 6 que establecía la Planta de 1761, gozaban de sueldo en calidad de criados del rey. Al prestar «continua y efectiva servidumbre», tanto en Madrid como en las Jornadas, hubo que aumentar su número, a 12 y «estableciendo entre ellos tres turnos cuatrimestrales, llamados cuarteles, a partir de enero de cada año», según lo hacían los capitanes de las Guardias de $\operatorname{Corps}^{22}$.

A pesar de este aumento, la proporción de 4 para los Reales Sitios se mantuvo, en una rotación que solía ajustarse a las preferencias del rey y a la propia disponibilidad de los sujetos, cuya categoría nobiliaria era explícita ${ }^{23}$. Aquellos a quienes se adjudicaba destino, junto al Príncipe o los infantes, solían desplazarse a los sitios formando parte de las diferentes «familias» que los acompañaban ${ }^{24}$.

Especialmente importantes en los traslados fueron los ayudas de cámara, un cargo que no tenía la significación nobiliaria de los anteriores. Era de promoción interna y suponía la entrada a un espacio inmediato al monarca. De los 18 de planta, solo los seis que disfrutaban de sueldo acompañaban en turnos de cuatro al monarca. Entre ellos, la presencia de los que procedían de Nápoles fue notoria, hasta el punto que, cuando les recompensó con alguna jefatura de oficios, guardarropa o tapicería, siempre lo fue con la condición de seguir desempeñando su función en la cámara ${ }^{25}$. El más presente fue Almerico Pini ${ }^{26}$, pero también Antonio Langlase, Diego Vernier,

${ }^{20}$ En la planta de 1764, para la Jornada de Aranjuez, los nombrados fueron el marqués de Castroponce, el conde de Atares, el duque de Hijar y el marqués de Belgida, (AGP, CIII, Leg. 100/2). En la de 1784, figuran el marqués de Valdeolmos, el conde de Castelblanco, Juan Pacheco, marqués de Tolosa, marqués de Campo de Villar y el marqués de la Torrecilla (AGP Reinados, C III Leg. 102/3 y Caja 680).

${ }^{21}$ Gómez-Centurión, “Al servicio”, 234-235.

22 R.O. 18 enero de 1786, comunicada por Floridablanca al marqués de Valdecorzana.

23 AGP CIV, Leg. 2/2. Gentileshombres de cámara con Exercicio..

${ }^{24}$ En la comunicación al duque de Losada de la R.O. 24 de abril de 1780 se especifica que de los ocho gentilhombres con entrada nombrados, dos, Navia y O'Reilly, servirían junto al infante D. Antonio. AGP, CIV Camara, leg.1 «Gentiles-hombres de cámara».

25 AGP Reinados Carlos III, leg. 120 /1 y 120/2. Jornadas de San Ildefonso y El Escorial 17601788.

${ }^{26}$ AGP Personal, caja 832/10. 
Nicolas de Arneaud, Juan Antonio Fleuriot, Pedro de Vera, Antonio M ${ }^{a}$ Cisneros. Ya al final del reinado, se incorporaron entre otros, Juan Fulgoso, Francisco Merlo o José Quipo del Llano. Pertenecían también a la cámara el Oficio de Guardarropa, los médicos de Cámara y los Secretarios de Cámara y Estampilla, igualmente presentes en los Reales sitios. Entre los facultativos que le acompañaban a los sitios estuvo con frecuencia Mucio Zona, que procedía de la familia italiana.

En el caso de las jornadas, casi tan importante como el personal de la cámara, era el administrativo, del que dependía el funcionamiento del viaje y la estancia. El contralor llevaba la parte financiera y de él dependían los pagos, las nóminas de mesillas y diversos gastos que detallaba al final de cada jornada. Tanto José de Guzmán como Agustín de Lanz, Mateo de Ocarranza o José Espárrago se sucedieron en el puesto durante el reinado ${ }^{27}$. No menos importante era el director de carruajes, que tenía a su cargo no solo los viajes, sino los aprovisionamientos y las comunicaciones durante la estancia. Desempeñaron el cargo Pedro Antonio Barles y Blas de Ibarra ${ }^{28}$. Un puesto importante, pero más humilde y peor remunerado, era el de oficial de Parte, encargado de mantener la correspondencia entre el Palacio madrileño y aquel en el que el rey estuviera residiendo. Pese a las prohibiciones, también servía para hacer llegar cartas y encargos del personal desplazado.

Entre las jefaturas de oficio, la de furriera era, la más importante ya que solía ir unida al cargo de aposentador de Palacio. Le incumbía la preparación de los sitios, el traslado de enseres, la distribución de espacios y el pago de los alojamientos que se alquilaban. Lo desempeñaron Miguel Merlo, Francisco Manuel Mena y Francisco García Echaburu, el primero y el último venidos de Nápoles y el segundo reconocido librero, que gozaron de la confianza del rey. El resto de los jefes de oficios no siempre iban a las jornadas, aunque elegían al personal que lo hacía. De todos ellos la representación de los oficios de boca fue especialmente numerosa. De las distintas cocinas que la componían, la española dejó de acudir y en la de boca destacaron los cocineros franceses Mateo Herve y Antonio Catalán, presentes en la mayoría de las jornadas $^{29}$.

Desde 1761 no hubo ni reina ni casa, pero la familia de mujeres siguió presente en las jornadas. La cámara se mantuvo y con ella la camarera mayor, condesa de Castropiñano, las azafatas Petronila Farias y la dueña Josefa Nelaton que habían venido de Nápoles. Junto a ellas un grupo de unas 20 mujeres, bajo la autoridad de la duquesa de Miranda que, como aya, atendía a los hijos pequeños del rey y a las infantas, que aumentaron con la llegada de la Princesa y el nacimiento de

27 AGP Personal, caja 31/20.

28 AGP Personal, caja 16538.

${ }^{29}$ AGP Reinados Carlos III, leg. 120 /1. Jornadas de San Ildefonso. 1761. Personal Caja 16780/37. 
nuevos infantes ${ }^{30}$. También estuvieron las que formaban parte de la cámara de la reina madre, hasta $1766^{31}$.

Cuando en 1760, se puso cuarto conjunto al príncipe Carlos y el infante D. Gabriel, la autoridad de la misma correspondió al duque de Béjar, cuyo nombramiento de ayo le obligaba a acompañar siempre a sus pupilos. También se nombraron dos tenientes de ayo, el marqués de Dusmet y caballero Marescoti, que eran genhilhombres con ejercicio del rey, con el que habían venido de Nápoles, dos mayordomos de semana y tres gentileshombres de cámara para el príncipe y otro, de manga, para el infante. A ambos servía un jefe de guardarropa y una pequeña representación de los oficios de furriera y tapicería. En 1762 se estableció «el cuarto y familia de hombres» para el Infante Antonio Pascual, con un teniente de ayo y un gentilhombre de manga y cuatro ayudas y, al año siguiente, el del infante D. Francisco Javier, similar en todo. Lo cual supuso que, a partir de esta fecha, se añadieran a las jornadas, además del duque de Béjar, un gentilhombre de cámara y un mayordomo de semana, 3 gentilhombres de manga, los maestros, José Barba y Juan Wedlingen, dos ayudas de cámara para el príncipe y seis más para los infantes Gabriel Antonio y Francisco Javier. También solía ir un maestro de dibujo y otros de música y baile $e^{32}$.

Con el matrimonio de los príncipes de Asturias, en 1765, el sequito se multiplicó, al dotarse a D. Carlos de un cuarto similar al de rey y dotarse de otro propio a D. Gabriel, similar al de los otros infantes ${ }^{33}$. Y hubo que formar otro para María Luisa de Parma que contaba con mayordomo, camarera y damas. La familia de mujeres que le recibió en San Ildefonso el 5 de septiembre estaba compuesta por la duquesa de Miranda, Cayetana Silva y Aragón, que la sirvió hasta su muerte en 1785, la marquesa de González, dueña de honor, que había venido con ella de Parma, donde fue como aya de su madre; Francisca de Rojas como azafata, cuatro camaristas, tres mozas de retrete y una de guardarropa ${ }^{34}$. Ya en Madrid, adoptó el modelo establecido para su suegra. La misma desproporción que se estableció entre la del príncipe y las de los infantes, hubo entre la princesa y las infantas que también tuvieron sus propias servidumbres individualizadas. Lo cual supuso que en la última jornada de Aranjuez de Carlos III, en 1788, hubiera seis familias de mujeres: la de María Luisa de Parma, bajo la autoridad de conde de Atares como mayordomo mayor y la marquesa de San Juan como camarera mayor, compuesta por 20 personas; la de su hija la infanta María Luisa, con 8; otra preparada para el inminente parto de la princesa, que sería el infante Carlos María Isidro, compuesta por 5; la de la infanta

30 AGP Reinados Carlos III, leg. 120 /2. Jornadas de San Ildefonso y El Escorial 1776.

31 AGP Administrativa. Casa, Leg. 785. Año 1761. Lista correspondiente para los criados y criadas de la Reyna Madre que han de servir en las próximas jornadas de Aranjuez (28 de marzo a 15 junio).

32 AGP. Reinados Carlos III. Leg. 210/1.

${ }^{33}$ En 1764 solo el traslado del cuarto del Príncipe entre El Buen Retiro y Aranjuez ocupó 28 calesas 58 mulas, 83 acémilas, 2 carros de 3 mulas, 3 coches de a 64 tiros. Buen Retiro 22 abril 1764 .

${ }_{34}$ AGP. CIII Leg 120/1 1765. Familia de criadas de la Princesa desde el 5 septiembre que llegó a San Ildefonso hasta el 28 noviembre que finalizó la jornada. 
Mariana Victoria de Portugal, de 9; la de su hijo el infante D. Pedro, de 6 y, finalmente, la de la infanta María Josefa, de 10. Un total de 58 personas, con sus carruajes y alojamientos ${ }^{35}$.

El número de los parientes directos que acompañaban al rey en las jornada fue casi siempre de unas nueve personas, pero distintas. En 1760 estas eran su esposa, su madre y hermano y seis hijos; en 1780, cuatro hijos, la infanta María Josefa, el príncipe Carlos, los infantes D. Gabriel y D. Antonio, dos consortes, María Luisa de Parma y María Ana Victoria de Portugal y tres nietos, Carlota Joaquina, María Amalia y Carlos Domingo. En 1788, el año de su muerte, solo conservaba tres hijos y una nuera, María Luisa, pero contaba con cinco nietos de los príncipes y otro más del difunto D. Gabriel.

\section{GOBERNAR DESDE LOS SITIOS}

El rey siempre era rey y aunque se desplazara buscando un entorno más agradable para satisfacer su afición a la caza y estar rodeado de un círculo más reducido de servidores y cortesanos, sus funciones eran las mismas y el gobierno de la Monarquía seguía pasando por sus manos. Un gobierno ya ensayado, caracterizado por el papel que en él jugaban las secretarías del despacho que, por su carácter unipersonal y su plantilla reducida, se adaptaba mejor a los traslados. Eran instituciones más ágiles en la toma de decisiones, cuyos procedimientos que trascurrían entre pocas personas y en comunicación directa con el rey, a través del despacho a boca y la vía reservada. Sus titulares, cumplían la voluntad regia, pero también la encauzaban, en un complejo equilibrio sujeto a muchos factores.

Cuando Carlos III llegó al poder había cinco departamentos ministeriales ya consolidados, Estado, Guerra, Hacienda, Gracia y Justicia y Marina e Indias, a cuyo frente estaban los secretarios del despacho, de los cuales, el de Estado, tenía categoría de primero, al modo de primer ministro. Las oficinas que siempre estuvieron en el Alcázar, pasaron al Buen Retiro, hasta instalarse en el Palacio nuevo, siempre en los bajos. En ellas trabajaban un número limitado de personas, entre las cuales los oficiales, entre 8 y 12, al estar en Palacio, pronto obtuvieron la consideración de criados del rey y pasaron a formar parte de la Real casa. Además, los titulares de Estado, Hacienda y Gracia y Justicia tenían competencias directas en la administración de la misma, tal y como confirmó el Reglamento de 1761. De ahí que su presencia junto al rey fuera indispensable y que el despacho de sus asuntos formara parte de la rutina del monarca, tanto en Madrid, como en los Sitios quedando así incorporados a la comitiva que se formaba para los desplazamientos, con derecho a trasporte, mesillas y alojamiento a cuenta de la Real Casa. En la ordenada rutina que presidía los días de Carlos III, cuyas mañanas quedaban reservadas para él mismo, la «hora de corte» empezaba al mediodía, con la comida,

${ }^{35}$ AGP, CIII, leg. 101/2. Aranjuez 8 marzo 1788. 
entre la "primera y la segunda entrada», en la cual lo hacían embajadores de familia, dignatarios, personal de la corte y los grandes cargos del reino que le acompañaban según la ocasión, la hora de los ministros estaba fijada después de la caza y antes de la cena, sobre las nueve y media y no solía prolongarse demasiado.

Hasta 1765 a las Jornadas solo iban los secretarios de Estado, Guerra y Hacienda, los cuales, en realidad eran dos por la acumulación de despachos. Pero una representación de cada oficina acudía a las jornadas. Así, por ejemplo, a la iniciada en Aranjuez el 28 marzo 1761, acudió Ricardo Wall como titular de Hacienda con 5 oficiales que llegaran a ser la plana mayor de la diplomacia española hasta finales de siglo, Agustín Llaguno, Juan Chindurza, Bernardo de Campo, Fernando Magallón, José Nicolás de Azara y Simón de las Casas, junto a dos porteros y un barrendero. Como también desempeñaba la secretaría de Guerra, por esta oficina iba el oficial mayor, José Portugués, más dos oficiales, portero y barrendero. El marqués de Esquilache, titular de Hacienda desde diciembre de 1759, se incorporó algo más tarde, acudiendo el oficial mayor, Pedro Martínez de la Mata, mas cinco oficiales, portero y barrendero ${ }^{36}$.

En 1763 la sustitución de Wall por Grimaldi en Estado, trajo como consecuencia que Esquilache pasara a desempeñar las de Hacienda y Guerra hasta 1766. Como en el caso anterior, ni Arriaga, que lo era de Indias, ni Muñiz, de Gracia y Justicia, acudían, no por desconsideración a sus departamentos, sino porque el monarca no tenía con ellos la misma sintonía personal que con los dos italianos ${ }^{37}$. Esto cambió con motivo de la larga jornada de Aranjuez de 1766, la de los motines. Entonces le acompañaron los cinco titulares, si bien Esquilache ya no lo hizo, al ser sustituido en Hacienda por Múzquiz y en Guerra por Gregorio Muniaín ${ }^{38}$. Así se mantuvo durante todo el periodo, incluido cuando, ya en los años ochenta, se desdobló la secretaría de Marina e Indias. La plantilla de las oficinas que se desplazaba, constituida por oficiales, escribientes, porteros y barrenderos, creció por el aumento de los primeros, quedando la oficina madrileña a cargo del oficial mayor, excepto en el caso de este tuviera que acompañar al rey, en sustitución del titular o por algún asunto concreto.

Un ejemplo fue la planta formada en 1785 para la Jornada de Aranjuez, compuesta por Floridablanca como titular de Estado y de Gracia y Justicia, ya que Manuel de Roda había muerto tres años antes, José de Gálvez en Indias, Antonio Valdés en Marina y López de Lerena en Hacienda y Guerra. Las oficinas estaban formadas por 8 oficiales, dos porteros y dos barrenderos en Estado; por el oficial mayor, 3 oficiales, 1 escribiente y 2 porteros en Gracia y Justicia; en Indias acudían 6 oficiales, 6 escribanos, 1 portero y dos barrenderos; en Hacienda, iba también el oficial mayor a pesar de acudir el secretario, 5 oficiales, y 2 porteros y en Guerra el oficial mayor, así como 4 oficiales, dos escribanos, 2 porteros y dos barrenderos. Un

36 AGP CIII, Leg. 91/2 Jornadas de Aranjuez de 1761, .28 marzo 1761.

${ }^{37}$ Ibídem, 1763.

38 AGP. Reinados Carlos III. Leg. 210/2. 
total de unos 50 individuos, cuyo número y categorías se mantienen hasta 1788 , aunque alternen las personas. En el caso de las batidas, cuya finalidad era la caza y su duración de pocos días, la presencia de los secretarios quedaba limitada al de Estado que acudía con algunos oficiales ${ }^{39}$.

Los secretarios y su oficina disfrutaban de transporte, acorde con su categoría. Así, en la citada jornada de 1785, el conde de Floridablanca disponía 4 mulas, 6 acémilas y un coche, lo mismo que los otros secretarios Gálvez, Valdés y López de Lerena, mientras que los oficiales de los cinco departamentos tenían calesa, mula y dos acémilas; los porteros una mula y los barrenderos una mula y $1 / 4$ de acémila ${ }^{40}$. En términos comparativos no cabe duda de la consideración de que gozaban, ya que el confesor real tenía 3 mulas, 3 acémilas y coche, el mayordomo Mayor, Marques de Santa Cruz, 6 mulas 8 acémilas y coche, y los de semana, 2 mulas y 4 acémilas; el contralor, calesa, 4 mulas y acémila; el sumiller, que era ya el marqués de Valdecarzana, 2 mulas y 4 acémilas, los gentilhombres, calesa y 4 acémilas y los ayudas de cámara, calesa y mula, el jefe de tapicería, Antonio $\mathrm{M}^{a}$ Cisneros, una mula y coche, y los uxieres de cámara, calesa compartida y acémila ${ }^{41}$.

La estancia en los sitios reales era incómoda para muchas familias que preferían separase para evitar gastos y que los hijos prosiguieran con sus estudios. Pero también era fuente de oportunidades. Los oficiales vivían de cerca la corte y se hacían notar; los secretarios del despacho encontraban más ocasiones de estar en contacto unos con otros, lo cual servía para contrastar opiniones o tratar asuntos compartidos, ya que el despacho con el rey siempre tenía carácter personal. De modo que las reuniones informales se institucionalizaron, a partir de 1763, a modo de junta de gabinete. Grimaldi, Esquilache y Arriaga lo hacían un día a la semana, generalmente los lunes, con objeto de tratar el estado de los negocios a su cargo y poder exponer mejor al monarca «los medios de mejorar su dirección en cada ramo». De la reunión estuvo excluido el titular de Gracia y Justicia, Muñiz, quizás por cuestiones personales, ya que su sucesor en 1765, Roda, el primer ministro español elegido por Carlos III, sí formó parte de ella, dejando de asistir entonces el de Marina e Indias, Arriaga. Con la llegada de Floridablanca, en 1777, la idea de reglamentar esta costumbre se fue abriendo paso, aunque solo diez años dio lugar a la Junta de Estado $^{42}$.

La práctica diaria del gobierno apenas era percibida por los cortesanos, excepto cuando había acontecimientos políticos de repercusión, como era la firma de tratados con otras potencias. Durante el reinado de Carlos III, seis de ellos se

\footnotetext{
${ }^{39}$ Así, por ejemplo en la que tuvo lugar en Aranjuez el 10 de diciembre de 1766, acudió Grimaldi con dos oficiales. AGP Leg. 130/1.

40 AGP, CIII, Leg. 100/2.

41 AGP, CIII, Leg. 101/2.

42 José Antonio Escudero, Los orígenes del Consejo de Ministros en España, 2 v., (Madrid: Editora Nacional, 1979).
} 
firmaron en los reales sitios tres con Portugal, dos con Francia y uno con Marruecos, todos los firmados en esto años en suelo español.

Aranjuez fue escenario de los dos franceses. El primero, ratificado el 3 de julio de 1777 por el conde de Floridablanca y el marqués de Ossun, embajador extraordinario de Francia y ministro plenipotenciario, establecía los límites fronterizos entre los territorios español y francés en la isla de Santo Domingo o La Española. El embajador, que estaba en España desde 1759, había obtenido la grandeza de primera clase en diciembre de 1765, en reconocimiento a los festejos que organizó para celebrar la boda de los príncipes de Asturias. Contaba con residencia propia en los sitios y ponía con este acto fin a su estancia.

Dos años después, el 12 de abril de 1779, se firmó el segundo tratado, entre el conde de Floridablanca y el conde de Vergennes, también en Aranjuez, que comprometía a España a intervenir en la guerra de Independencia de los Estados Unidos. Era un compromiso derivado del Tercer Pacto de Familia y dirigido contra Inglaterra por el que España pretendía recuperar Gibraltar y Menorca, la Florida y la Honduras Británica.

Tras el tratado previo, negociado en Marruecos por Jorge Juan y su rompimiento en 1775, se firmó en Aranjuez, el 30 de mayo de 1780, un nuevo convenio de amistad y comercio con Marruecos por el conde de Floridablanca y Mohamed Ben Otoman, en el que se establecía la recíproca libertad de comercio. El embajador marroquí, un hombre culto y curioso, en su recorrido desde Marruecos a la corte, viajó pausadamente y visitó muchas localidades, dejando escritas las etapas de su periplo. Vino acompañado por 14 personas y la estancia duró desde el 17 de diciembre de 1779 en que desembarcó en Cádiz, hasta que volvió a embarcar para Ceuta en agosto de 1780. Llegó a Madrid el 12 de enero y se alojó en el Buen Retiro, hasta ser recibido en El Pardo el 22 de enero, donde residió, visitando después los sitios reales y, en especial la biblioteca del Escorial, para finalizar su tour en Aranjuez donde se firmó el convenio ${ }^{43}$.

De los tratados con Portugal, el primero fue el de El Pardo, firmado el 12 de febrero de 1761, que anulaba otro anterior, el de 1750, que no había logrado llevarse a cabo por la resistencia de los guaraníes y la negativa de los jesuitas, a salir de sus pueblos en las Misiones Orientales del Uruguay. El segundo, firmado el $1^{\circ}$ de octubre de 1777 en San Ildefonso, establecía las fronteras entre ambos países en el continente sudamericano. Los portugueses cedían la mitad sur del actual Uruguay, incluida la colonia de Sacramento, a España, así como las islas de Anabón y Fernando Póo en Guinea, a cambio de la retirada española de la isla de Santa Catalina. Después de su firma, en el deseo de consolidar las relaciones entre ambos países, se empezó a tratar sobre una posible visita de la reina viuda portuguesa,

43 Vicente Rodríguez Casado, Política marroqui de Carlos III (Madrid, 1946), 285-306. La audiencia concedida por Carlos III a Mohámed ben Otoman aparece reflejada en un cuadro de P.P. Montañes. 
hermana de Carlos III, a España. En su presencia se firmó el Tratado del Pardo de 11 de marzo de 1778 entre María I de Portugal y Carlos III, dirigido a resolver las disputas territoriales en esa región que habían provocado dos conflictos, entre 1761 y 1763 y 1776 y 1777.

Con motivo de este último tratado vino a España la reina viuda, la infanta Mariana Victoria, que llegó a El Escorial el 4 de noviembre 1777 y permaneció un año en la Corte, junto a su hermano y el resto de la real familia. Después pasó a San Ildefonso y a Madrid el 2 de diciembre, para trasladarse a Aranjuez el día 10 con la infanta María Josefa y volver a pasar la Navidad en el palacio madrileño. Ya en enero siguió a la corte al Pardo y se incorporó al periplo establecido hasta el 5 de noviembre de 1778 en que emprendió el viaje de vuelta ${ }^{44}$. Dado el cambio que la muerte de José Í supuso en las relaciones hispano portuguesas y el interés del rey y de Floridablanca por mejorarlas, la significación política de la estancia es grande, máxime cuando ambos tenían ya en el horizonte los matrimonios portugueses que se celebrarían en 1785 .

Los presidentes de los consejos y otros altos cargos de la monarquía también solían incorporarse a las jornadas pero, institucionalmente, no formaban parte de la Real Casa, excepto a título personal, si tenían algún nombramiento. La presencia del Inquisidor General, al no ser ya confesor regio, a partir del retiro de Bonifaz en 1774, tampoco fue constante. El presidente del de Castilla si solía acudir a las Jornadas. Desde luego lo hizo el conde de Aranda, que podía hacerlo a título propio y Campomanes, antes y después de su nombramiento efectivo como tal en 1786.

\section{EL COSTE DE LAS JORNADAS}

Después de más de un siglo de práctica, la mecánica de los sitios estaba perfectamente engranada: se hacían listas y más listas, de criados, carruajes y alojamientos, se preparaban los asientos, con salarios y mesillas; se fijaban tempranamente las fechas de salida y llegada de la comitiva y se movilizaban los muebles, tapices, esteras e, incluso, utensilios de cocina, que debían transportarse, procurando que no se estropearan, ni se perdieran en el camino. Contrastando con tanta diligencia, los responsables no dejaban de avisar a las más altas autoridades, el mayordomo mayor y al secretario de despacho de Hacienda, por lo que afectaba al presupuesto, sobre el viejo problema del alojamiento de se había hecho acuciante: es decir, resultaba imposible albergar debidamente a un sequito cada vez más numeroso. Un problema, que se multiplicaba en otros muchos, porque tanto los grandes de España como los responsables de las principales instituciones, no iban solos, sino con parte de su casa o de su oficina, y del noble de linaje o la dama encopetada al

44 Paulo Drumond Braga, A rainaha discreta. Mariana Vitoria de Bourbon, (Lisboa: Circulode Leitores, 2014), 220-236. 
burócrata más discreto, todos gustaban de ir acompañados por familiares y de ser servidos por sus propios criados.

Una realidad compleja, difícil de manejar por las apreciaciones comparativas que entrañaba y lo inevitable de medir en términos de prestigio tanto la calidad del aposento como la menor o mayor cercanía a la residencia regia.

El departamento encargado de gestionar este conglomerado era la Furriera y su jefe el que adjudicaba los cuartos en las dependencias reales o inspeccionaba los que se tomaban en casas particulares, alquiladas al efecto. También quien debía autorizar las obras necesarias para que fueran habitables año tras año. Un escrito dirigido al duque de Béjar, mayordomo mayor del príncipe D. Carlos por la oficina del contralor general y comunicado al marqués de Montealegre que lo era del rey, fechado en El Pardo, el 29 de enero de 1769, exponía cual era la situación en esas fechas y la necesidad de implicar al secretario de Hacienda, Muzquiz, dado que cualquier arreglo suponía un gasto adicional. En aquel sitio y en esas fechas no había ya posibilidad de alojar al creciente número de personas que servían a las personas reales en los edificios que el rey tenía destinados para ello. Estaban sobrecargados y tesorería, agobiada con las obligaciones de la corona, no podía afrontar el gravamen que supondría construir nuevos edificios o alquilarlos, como se venía haciendo en Aranjuez. La solución era redistribuir y descentralizar el gasto, para lo cual proponía que de las familias de los infantes Gabriel, Antonio y Francisco Javier, el mayordomo mayor solo diese alojamiento en palacio a aquellas personas que les servían «inmediata y continuamente» y que, al resto, fueran los infantes quienes les sufragasen el alojamiento de sus bolsillos, ya fuera alquilado, comprado o de nueva construcción, de manera que no gravasen los gastos de la Real Casa ${ }^{45}$. La petición iba acompañada de la relación de los criados de los infantes llevaban a las distintas jornadas de los sitios, 20, 18 y 13 respectivamente, a los que había que añadir los 32 del hermano del rey, D. Luis, y los de la infanta María Josefa que, aunque se servía por los de la familia del rey, mantenía aparte un ayuda de oratorio, zapatero, maestro de clave, templador y un mozo de guardajoyas. Un total de 88 personas. La comunicación dejaba claras tres cuestiones: la saturación de alojamientos y la necesidad de abordar posibles soluciones como, al parecer, ya se habían adoptado en Aranjuez; la dificultad de afrontar los gastos extraordinarios que, alquilar o construir, podía suponer; y los perniciosos efectos, tanto espaciales como económicos, de la multiplicación de «familias».

Pero no eran solo los infantes quienes generaban estos problemas. Incluso las dependencias de que el rey disponía para el alojamiento de su propia servidumbre en cada sitio hacía tiempo que estaban saturados, lo que había obligado a algunos a procurárselos por su cuenta, mientras que a otros se los proporcionara la Casa real, que los alquilaba ex profeso según atestiguan las partidas que figuran en los gastos de las jornadas. Camufladas entre los muchos gastos que debían atenderse, fue a partir

\footnotetext{
45 AGP, Administrativa, caja 9484/22.
} 
del nombramiento de Francisco José de Mena como jefe de furriera y de su sucesor, García Echaburu, cuando los alquileres empezaron a crecer. En el caso de San Ildefonso entre 1774 y 1775 alcanzaron casi el gasto de mesillas con más de 300.000 rs. ese último año, disminuyendo a menos de la mitad en 1779, para mantenerse entre los 136.000 y 167.000 hasta 1784 , mientras las mesillas oscilaban entre los 253.000 rs a los 267.000 reales, en cifras aproximadas. Hubo dos años de gastos extraordinarios, 1785 y 1786, debido a los dobles matrimonios portugueses celebrados en Madrid y Lisboa en marzo y abril de 1785.

A comienzos de ese año, Floridablanca, entonces secretario de Estado y de Gracia y Justicia, tuvo que intervenir, por una R.O. 11 enero 1785, para que se abordara el problema y terminar con las quejas y reclamaciones que las adjudicaciones generaban. En consecuencia, el mayordomo mayor, duque de Medinaceli y el caballerizo mayor, conde de Villena, mandaron hacer una relación detallada de donde se alojaba cada criado desplazado y, en el caso de los alquilados, a cuanto ascendía esta partida. El resultado fue tres grandes conjuntos de planos estudiados con detalle por Javier Fernández que son una verdadera radiografía del tema que nos ocupa ${ }^{46}$. Relaciones y planos se habían hecho con anterioridad, pero el antecesor en la Furriera, Francisco Manuel de Mena, no lo hizo, con la consecuente confusión. Para remediarlo, en los casos de El Pardo, Aranjuez y el Escorial, se recurrió a José Merlo Fernández, hijo de José Merlo, fallecido en 1774, nieto de Manuel de Merlo, escribano de cámara del Consejo y sobrino de Diego y Bernardo, que habían sido aposentador de Palacio y aposentador honorario, respectivamente, cuyas conexiones familiares aseguraban su conocimiento del tema. Era entonces entretenido y encargado de limpieza en palacio madrileño, pero se le ascendió a ayuda de furriera el 18 de julio de $1785^{47}$.

No era inexperto, ya que supo rodearse de delineantes y escribientes, no pocos vinculados a la Furriera, que cumplieron con el cometido de levantar planos con un coste de 28.311 rs. de vellón. Entre ellos figura el general de cada población estudiada y los de las casas del rey, con sus diferentes cuartos y la relación de los ocupantes según categorías y familias. En San Ildefonso de la Granja, el encargado de hacerlo fue Domingo Maria Sani, hijo de Domingo Maria Sani, aposentador de ese palacio y del de Valsain, que ocupaba el cargo de conserje de palacio y, desde 1777, de ayuda honorario de Furriera, hombre de confianza de Echaburu y de Grimaldi y encargado del aposentamiento durante el verano en S. Ildefonso ${ }^{48}$.

Caso distinto fue el de El Escorial, donde ya Herrera proyectó y Francisco de Mora, construyó dos casas de oficios. Además, la estructura del monasterio permite alojar más personas, aunque ocupando cada vez más celdas y recurriendo también a casas particulares. Afectado por un grave incendio en 1763, tras la llegada de

\footnotetext{
${ }^{46}$ Javier Fernández Fernández, "José de Merlo y los planos de 1785 para el alojamiento de la Real Comitiva en los Reales Sitios" en Una corte para el rey, 236-247.

47 Ibídem y AGP Personal. caja 677, exp. 22.

48 Ibídem. AGP. Personal.
} 
Villanueva, que era el arquitecto de la orden jerónima, la población empezó a cambiar con la construcción de un edificio para la familia de los criados de los infantes en 1771. También inició la Casita del Príncipe y la del infante D. Gabriel o de Arriba, que eran pabellones de recreo. Ya en 1785, el propio Floridablanca le encomendó el alojamiento del secretario y la secretaría de Estado, que no quedó terminado hasta 1797, con la construcción del puente para unirla a la segunda casa de oficios $^{49}$.

El marqués de Villena cumplió el mismo encargo respecto a las caballerizas y ballestería. Todo lo cual, fue entregado a Merlo para que preparara la relación general de quienes debían ocuparlos. La muerte de Carlos III en diciembre de 1788 truncó este propósito, ya que su hijo cambió el ciclo de los sitios, prescindiendo de El Pardo y privilegiando la estancia en Aranjuez hasta casi seis meses. Merlo continuó como jefe de Furriera y aposentador general de Palacio honorario, no siéndolo efectivo hasta 1805.

Tan interesante como las relaciones de quienes se aposentaban en las casas del rey son las listas de las casas alquiladas, sobre las cuales cabe establecer una tipología no solo de los ocupantes sino de los arrendadores. Por ejemplo, la realizada el último año de la vida del rey, cerrada el 25 de junio, resulta especialmente significativa porque el sistema estaba ya consolidado y se refería a un sitio que había sido pionero en abordar el problema ${ }^{50}$. Entre los arrendadores no faltan títulos significativos como el conde de Atares, el marqués de Iranda y los de Perales, Murillo y de Salas, los cuales alquilan buenas casas a precios altos. Así, Iranda, cedió una por 12.000rs. al embajador de Nápoles y otra más modesta de 2.700 al Antonio M. Cisneros, jefe de tapicería y ayuda a de cámara. Murillo alquiló otra por 9000rs. al secretario de Marina, Valdés y el marqués de Salas, otra con 13 habitaciones separadas, cocheras y un cuarto por 6.600. Había también propietarios que alquilaban varias casas de distintas categorías cuyos precios que oscilaban entre 9.100 rs. y 340rs. En este tipo de alquileres múltiples había no solo viviendas, sino buhardillas y cocheras y se trataba de un buen negocio, lo que explica que quienes los heredaban y las viudas rentabilizaban así este patrimonio, incluso antes de ser repartido. Las formas de aprovechamiento eran muchas: así, por ejemplo, Manuel de la Puerta, tenía dos casas, una alquilada por cuartos, guardillas, caballeriza y cochera y otra nueva, con bajos, que alquilaba entera, mejor propiedad pero menos rentable. Una práctica que era habitual entre los propietarios de un solo inmueble, que ganaban más alquilándolo por cuartos o habitaciones. Los propios empleados de la Real Casa participaban en el negocio, como Felipe Viergol, que alquilaba su casa para el personal del cuarto del Príncipe y se alojaba en la que le correspondía por desplazarse. No faltaban quienes percibían directamente el dinero para el alojamiento, que se habían procurado personalmente. D. Blas de Lezo y el marqués de Torrecilla

\footnotetext{
${ }^{49}$ José Luis Sancho, "Carlos III, "de monte en monte", 244-247 y Carlos Sanz de Miguel, "El aposentamiento de San Lorenzo del Escorial", Una corte para el rey, 184-187.

${ }^{50}$ Lista y recibo general de las casas alquiladas en el Real Sitio de Aranjuez. en la presente jornada del año 1788 para diferentes criados de S.M.y S. AGP... Reinados, Carlos III, leg. 103/3.
} 
cobraron por ello 3.000rs., pero D. Manuel Espejo, de menor categoría, solo 1.300 rs. Los alquileres medios de vivienda oscilaban entre 1.200 y 3.000 euros y los cuartos de los 300 a los 800 y ese era el dinero que se les rembolsaba. Hay también propietarios que arriendan solo caballerizas y cocheras, por un precio bastante más bajo o, incluso, habitaciones en la propia casa. En cualquier caso, todo indica que la demanda de la corte se aprovechó para hacer negocio, rentabilizando no pocos inmuebles con los alquileres e, incluso, construyendo otros, exprofeso para ello ${ }^{51}$. Todo lo cual explica que, los alquileres, sin alcanzar nunca los gastos de carruajes que los doblaban y siendo inferiores a las mesillas, constituyeran la tercera partida de gasto de la Casa real.

No es extraño que las jornadas reales resultasen cada vez más costosas para la Hacienda, duplicando sus gastos entre 1760-65 y 1788 en que alcanzaron los 5 millones y medio de reales, por mucho que su titular intentara disminuirlos. También suponían una carga para los pueblos por los que pasaban que debían «arreglarse»y, con frecuencia, ofrecer medios de transporte complementario. Como contrapartida, proporcionaban trabajo, animaban el mercado y solían beneficiarse de alguna gracia, colectiva o individual ${ }^{52}$. La presencia del rey, aunque fuera dentro de un carruaje, en teoría, renovaba los lazos con los súbditos, siempre, claro, que la tranquilidad del reino estuviera asegurada, lo cual no ocurrió en la primavera de 1766. Entonces, o mejor dicho, unos meses más tarde, en vísperas de volver a Madrid, se intentó contener los gastos, por razones más que económicas, políticas, procurando, tal y como explicó el nuevo secretario de Hacienda, Muzquiz, al sumiller, Duque de Losada, y este trasladó al contralor, Gabriel Benito Alonso López, al objeto de evitar, de cara a 1767, cualquier gasto superfluo en la Real Servidumbre ${ }^{53}$. No fue la única vez en que se hizo esta recomendación, que se repitió en 1770, con resultados más positivos y en 1786. Entonces, el secretario de Hacienda, Pedro de Lerena, exigió al controlador una memoria que explicitase los recortes que debían hacerse en cada departamento, para ser discutida por la Junta de jefes de la Real Casa.

El resultado fue desalentador. Como dejó claro el contralor, José Espárrago, las memorias que le habían enviado los distintos jefes de los oficios, que él resumió y contrastó en un detallado y crítico informe, fechado en San Ildefonso el 14 de septiembre de 1785, eran cuanto menos, poco satisfactorios. De las respuestas recibidas de las 12 jefaturas de oficios, la mayoría eran complacientes con la situación que tenían y las más críticas se fijaban más en los defectos ajenos que los propios. En relación con los de Furriera y Tapicería, sus comentarios eran incisivos y expresados con una libertad sorprendente en un servidor del Antiguo Régimen. El jefe de la primera, Francisco García Echaburu, se había limitado a proponer una cierta renovación de su plantilla, sin darse por enterado de los «abusos infinitos» que se producían en los alojamientos, de los que se benefician «músicos», «escultores», «marmolistas», dependientes del trono y no de la Casa, así como los artesanos y

51 AGP. Reinados Carlos III. Leg. 130/2.

52 Jurado Sánchez, El gasto de la Casa Real, 137-138.

53 AGP. Reinados Carlos III. Leg. 210/2. Comunicados de 21 y 23 noviembre de 1766. 
ojeadores, no comprendidos en la lista de gente de la jornada, pero por los que se pagaba $60.000 \mathrm{rs}$ al año. Tampoco entiende que se den cuartos a los de ballestería, poco útiles, y que vayan tantos oficiales, porteros y barrenderos con las secretarías, con un coste de más de 400.000 al año en alojamientos, esterados y reformas. Igualmente señalaba que las desproporcionadas dimensiones de los alojamientos de los mayordomos mayores, sumilleres y ministros, eran la causa principal de que las casas reales resultaran insuficientes. Recuerda que, en Nápoles, todo estaba ordenado y controlado y se pregunta porque no ocurre lo mismo en España. Respecto al jefe de Tapicería, Cisneros, su informe no resulta más complaciente: trasladaba más cosas de las necesarias, con el consiguiente gasto en carruajes y prestaba demasiados muebles a los jefes que, a su vez, los cedían a otros, con el consiguiente deterioro o, incluso, pérdida, de los mismos. Para dar mayor fuerza a sus palabras presentaba un cuadro detallado con datos concretos de los abusos de estos dos departamentos, cuyo descontrol procedía de la concesión que les hizo en 1760 el duque de Alba, de que no estuviesen sujetos al contralor que, aunque fue rectificada por el reglamento de 1761, nadie intentó aplicar.

Según Espárrago, en 9 años se habían gastado 7.972.960,23 rs. en alquileres, 965.613,17 en carpintería, 638.923, 14 en cerrajería y 416.725,37 en vidrieras, lo cual sumaba 9.993.323, 24 rs. Desglosados por sitios, los alquileres, habían supuesto: El Pardo 1.003.419 rs.; Aranjuez: 2.395.845, 17 rs.; San Ildefonso 2.227.293,16rs.; San Lorenzo: 2.296.903 $\mathrm{rs}^{54}$. Eran cifras importantes, pero a la Junta, en la que intervino activamente el duque de Losada, no le gustó el informe del contralor, que se juzgó poco respetuoso.

\section{CONCLUSIONES}

Es verdad, como escribió el Conde de Fernán Núñez, que Carlos III fue un hombre «virtuoso, familiar y sencillo». Que llevó una vida ordenada, tuvo gustos sobrios y trató de no hacer cambios, ni en su vida, ni en su casa. Es más, su corte fue tildada de austera y así les pareció también a los príncipes de Asturias. El duque de Losada contribuyó a preservar la intimidad de sus habitaciones privada, junto a unos ayudas de cámara que envejecieron a su lado, como fue el caso de Almerico Pini. La continuidad en el gobierno también fue su objetivo, aunque se vio forzado a prescindir de Esquilache y tuvo que sustituir a Roda que falleció tras 17 años de secretario. El conde de Floridablanca fue su legado a su hijo. A los tres ennobleció, en 1755 y en Nápoles, en 1782, a título póstumo y en 1773, sin importarle que el primero hubiera sido inspector de aduanas, los otros dos, golillas y los tres tan regalistas como anti romanos. Con Aranda su relación fue menos cómoda, ya que su carácter llegó a molestarle. En cualquier caso, a pesar de esta inclinación por los "medianos", en Madrid o en los sitios, siempre necesitó un marco suntuario que

${ }^{54}$ AGP CIII, leg.155/2 
realzara su imagen y consideró su obligación de rey mantener su corte con la brillantez adecuada para ser el escenario del ejercicio de su gracia.

Viudo desde 1760 fue un hombre un hombre de familia y siempre quiso que hijos y nietos le acompañaran. Hubo afecto en su relación, pero también, como le habían inculcado sus padres, el convencimiento de que eran parte inseparable de la representación de la Corona y que, por ello, debían representarse con la dignidad y el boato que exigía su estirpe.

En definitiva, el crecimiento de la Real Casa, de sus gastos y personal, la misma disfuncionalidad de las cortes estacionales, resultó difícil de atajar, sin que las reformas, bien intencionadas, pero poco firmes, sirvieran de mucho. Años tras años se promulgaron órdenes de contención del gasto y este, con leves oscilaciones, siguió subiendo. Hubo oposición en la propia casa a introducir reformas, demasiadas voces compresivas ante lo que se consideraba consustancial a la magnificencia regia y algunas críticas. El propio rey autorizó individualmente a conculcar prácticas que él mismo había establecido, como la duplicidad de cargos y sueldos. Permitió que otros se enriquecieran con los desplazamientos y prefirió ignorar cualquier sospecha sobre las personas de su confianza. En el último año de su reinado, no debió ser León de Arroyal el único que juzgaba escandaloso que sumaba más «una sola partida de Palacio y Sitios Reales que, en otros tiempos, todos los gastos de la Monarquía» 


\section{BIBLIOGRAFÍA}

León de Arroyal, Cartas político económicas al Conde de Lerena. Madrid: Ciencia Nueva, 1968.

Selina Blasco, "Viajeros por Aranjuez en el siglo XVIII. Antología de descripciones" en El Real Sitio de Aranjuezy el arte cortesano del siglo XVIII. Madrid: Patrimonio Nacional, 1787, 41-136.

Carlos III: cartas a Tanucci (1759-1763). Prólogo de Gonzalo Anes. Introducción, transcripción y notas de Maximiliano Barrio. Madrid: Banco Bilbao Vizcaya, 1988.

Paulo Drumond Braga, A rainaha discreta. Mariana Vitoria de Bourbon. Lisboa: Circulo de Leitores, 2014.

José Antonio Escudero, Los orígenes del Consejo de Ministros en España, 2 v. Madrid: Editora Nacional, 1979.

Javier Fernández Fernández, "José de Merlo y los planos de 1785 para el alojamiento de la Real Comitiva en los Reales Sitios" en Una corte para el rey, Carlos III y los Sitios Reales. Madrid, Comunidad de Madrid/Patrimonio Nacional, 2016, 236247.

Hiltrud Friederich-Stegmann, La imagen de España en los viajeros alemanes del siglo XVIII. Alicante: Universidad, 2014.

Carlos Gómez Centurión, "La Reforma de las casas reales del Marques de la Ensenada" en Cuadernos de bistoria Moderna, 20 (1998), 59-83.

José Jurado Sánchez, El gasto de la Casa Real. Su financiación y sus repercusiones hacendísticas y económicas. Madrid: I. E. Fiscales, 2000.

M. Victoria López-Cordón Cortezo, "Servir y seguir al rey. Séquitos, desplazamientos y alojamientos en las "jornadas", en Una corte para el rey. Carlos III y los sitios reales, Madrid, Comunidad de Madrid, Patrimonio Nacional, 2016, pp.64-81.

Francisco Javier Plaza Santiago, Investigaciones sobre el Palacio Real Nuevo de Madrid. Valladolid: UVA, 1975.

Vicente Rodríguez Casado, Política marroqui de Carlos III. Madrid, 1946.

Delfín Rodríguez Ruíz, coord., Francisco Sabatini. La arquitectura como metáfora de poder. Madrid: Electo, 1993. 
José Luis Sancho, "Madrid y los sitios reales" en Una corte para el rey. Carlos III y los Sitios Reales. Madrid: Comunidad de Madrid/Patrimonio Nacional, 2016, 95114.

José Luis Sancho "Carlos III, "de monte en monte". Cinco poblaciones para una corte", en Una corte para el rey. Carlos III y los Sitios Reales. Madrid: Comunidad de Madrid/Patrimonio Nacional, 2016, 115-175.

José Luis Sancho y Gloria Martínez, “¿Dónde está el rey? El ritmo estacional de la corte española y la decoración de los reales sitios (1650-1700)", Cortes del Barroco. De Bernini y Velazquez, a Giordano, eds. Fernando Checa. Madrid: Acción Cultural Española/Patrimonio Nacional, 2003, 85-97.

Carlos Sanz de Miguel, "El aposentamiento de San Lorenzo del Escorial", Una corte para el rey. Carlos III y los Sitios Reales. Madrid: Comunidad de Madrid/Patrimonio Nacional, 2016.

Recibido: 21 de julio de 2018 Aprobado:23 de octubre de 2018 